\title{
BACKWARD AND FORWARD LINKAGES IN MANUFACTURING LOCATION DECISIONS RECONSIDERED
}

\author{
Frank L. Hefner and Paulo P. Guimaraes*
}

\begin{abstract}
Backward and forward linkages are often cited as both determinants of plant location and as desirable factors in targeting potential firms. This paper models manufacturing investment decisions within a state economy. We use a conditional multinomial logit model and find that both types of linkages are significant. We further note that per capita income and the number of workers employed in manufacturing within the region are also significant in the location decision.
\end{abstract}

\section{INTRODUCTION}

Linkages continue to be on the list of factors that determine the desirability of a site. Studies that target industries for industrial recruitment often include linkages as one of the criteria. The Midwest Research Institute and Battelle both use linkages in their screening process to determine which industries regional planners should target (see Minshall and Wright 1990; Morton 1990). Anderson and Johnston (1992), for example, presume that linkages provide a good measure for determining prospects for industrial location in Alabama. In this note, we investigate whether linkages are statistically relevant in the site location decision. As Blair and Premus (1987) note, the literature is already voluminous. Our contribution to this literature is to reevaluate the relevancy of linkages in a substate model of industrial location.

Linkages have been categorized into two types: backward and forward. Backward linkages refer to the demand-side connections a firm has with other existing firms in the region. Anderson and Johnston (1992) review the previous research on linkages and apply interindustry data to calculate the size of these linkages for Alabama. From an input-output approach, these linkages are the intermediate demands that a firm makes on other firms within the region. These demand-related connections are important both from the planning point of view and from the firm's perspective. From the planner's point of view, the impact of a

\footnotetext{
*Research Economist and Assistant Professor of Economics, Division of Research and Department of Economics, College of Business Administration, University of South Carolina, and Professor, Faculdade de Economia, Universidade do Porto, and Instituto Nacional de Investigacao Cientifica. A version of this paper was presented at the North American Regional Science Association International Meeting, New Orleans, November 7-10, 1991. This revision benefitted from the helpful comments of two anonymous referees.
} 
new firm on the local economy depends on the size of its backward linkages. From the firm's point of view, the size of the existing backward linkage indicates the availability of suppliers for inputs into its production process. ${ }^{1}$ Transportation costs are potentially reduced by locally supplied inputs. Proximity to suppliers also potentially reduces the need for inventories as just-in-time controls may be used.

Forward linkages refer to the supply-side connections a firm has with other existing firms in the region and provide a measure of the size of the potential market for an entrant into the region. For example, many manufacturing firms produce for interindustry demand rather than for final consumption.

A number of researchers have utilized varying measures of linkages to investigate their contribution to the location decision. Okansen and Williams (1984) looked at the linkage connection in plant location in Canada. McAleese and McDonald (1978) and O'Farrell and O'Loughlin (1981) found that local linkages are relevant to firms using perishable inputs. Latham (1976) noted that linkages were significant for firms using raw materials. Those firms that have unique input requirements would be expected to require strong links in the local economy. Anderson and Johnston (1992) provide a recent review of the literature, citing evidence that the interindustry connections among industries are relevant to the site location decision.

In this note, we investigate the determinants of the choice to locate within a state. In a sense, this approach lends itself to a nested decision method. On the first level, the decision maker decides on the state. In this case, the research of Carlton (1983), Wayslenko and McGuire (1985), Bartik (1985), Woodward (1992), and others provides evidence of the determinants of this decision. At this level, tax considerations, differing state development incentives, union bias, energy costs, and other factors that may have significant interstate variation, but would be similar almost everywhere within a state, must be taken into account. ${ }^{2}$ In our paper, we consider the second level decision. The state has been chosen, and now the firm must choose which area within the state to locate. Within the same state, development initiatives, union bias, energy costs, and the whole host of state-specific variables that must be controlled for in the decision to pick the state are no longer relevant. Thus, we focus more explicitly on the effect of the linkages. $^{3}$

Our model investigates the location decision within the state of South Carolina. The South Carolina State Development Board has provided data on capital investments by county by SIC code. These investments represent both new and existing plant expansions. Following the research methodology of Bartik (1985), Carlton (1983), and Woodward (1992), we employ a conditional multi- 


\section{FIGURE 1}

Substate Location Decision Choices

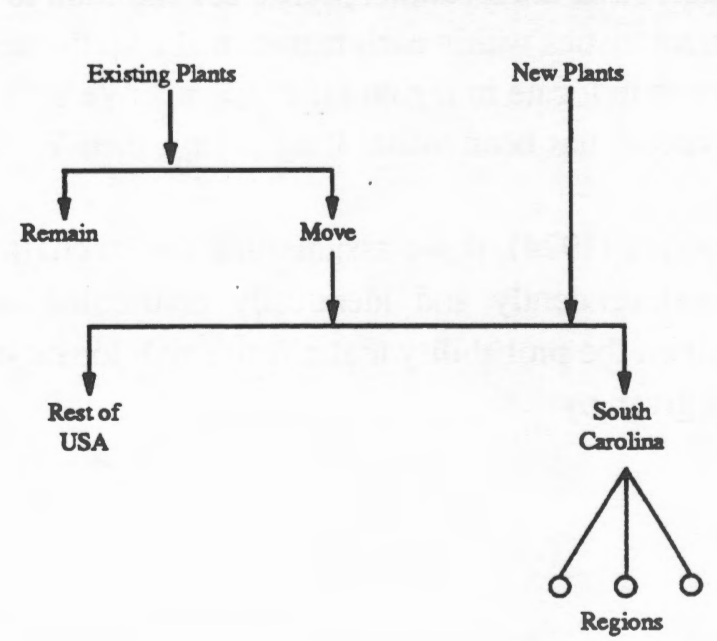

nomial logit model that incorporates backward and forward linkages in addition to a set of other region-specific variables.

\section{MODEL}

Once a firm decides to invest in South Carolina, it has a limited number of well-defined locations from which to choose. We adopt the standard classical assumption that firms are profit maximizers, and thus the decision to locate an investment project is determined by the profitability of that project associated with a particular location. The conditional multinomial logit model is the procedure best suited for estimating location probabilities. ${ }^{4}$ We assume that, associated with each location, there is a profit, $\pi_{\mathrm{ij}}$, which is a sole function of the characteristics of that location and is composed of a systematic and a stochastic component defined as follows:

$$
\pi_{i j}=\beta X_{i j}+\lambda X_{j}+\varepsilon_{i j}
$$

where $\pi_{\mathrm{ij}}=$ the profit of firm $\mathrm{i}$ located in region $\mathrm{j}$,

$\mathrm{X}_{\mathrm{ij}}=\mathrm{a}$ vector of both choice and individual specific variables,

$\mathbf{X}_{\mathbf{j}}=$ a vector of choice-specific variables,

$\varepsilon_{i j}=$ stochastic component,

$\beta, \lambda=$ vector of coefficients. 
The backward and forward multipliers are examples of the types of variables that comprise the vector $\mathrm{X}_{\mathrm{ij}}$; that is, these variables are specific to the firm for each specific region. Variables that are location specific but common to all firms, such as the labor force characteristics within each region, make up the vector $\mathbf{X}_{\mathbf{j}}$.

A firm $i$ will choose to locate in region $j$ if $\pi_{i j}>\pi_{i k}$. We let $Y_{i j}$ be a random variable indicating a choice has been made. If $\pi_{\mathrm{ij}}>\pi_{\mathrm{ik}}$, then $\mathrm{Y}_{\mathrm{ij}}=1$ and $\mathrm{Y}_{\mathrm{ik}}=0$ for $j \neq k^{5}$

Following McFadden (1974), if we assume that the stochastic terms of the profit function are independently and identically distributed according to a Weibull distribution, then the probability that a firm $i$ will locate in region $j$, i.e., $P_{i j}=\operatorname{Prob}\left(Y_{i j}=1\right)$, is given by

$$
P_{i j}=\frac{e^{\mu \pi_{i j}}}{\sum_{j=1}^{n} e^{\mu \pi_{i j}}}
$$

where $\mu$ is a constant. These probabilities are really conditional probabilities; namely, they are conditional on the decision to undergo new investment.

An advantage of the conditional multinomial logit model over the standard logit model is that the model allows for the selection probabilities to depend upon the available alternatives and the individual decision makers. Bartik (1985) notes that one of the problems in applications of the conditional logit model to business location decisions is that it is generally impossible to use the true alternatives. In our case, however, the firm has decided to locate in South Carolina, and the set of alternatives within the state is finite. ${ }^{6}$ Thus, we may completely specify the alternatives.

\section{VARIABLES AND DATA}

The 46 counties of South Carolina have been aggregated into eight economic regions. Each of these regions contains a principal node, mostly in the form of an MSA. The regions were determined by examination of commuting patterns to assess employment linkages. ${ }^{7}$ The break up of the state is depicted in Figure 2.

Thus, the index $j \mathrm{j}$ ranges from 1 to 8 . These regions constitute the limited set of choices in the location decision in our analysis. The model then determines the probability of location within one of the eight regions. 


\section{FIGURE 2}

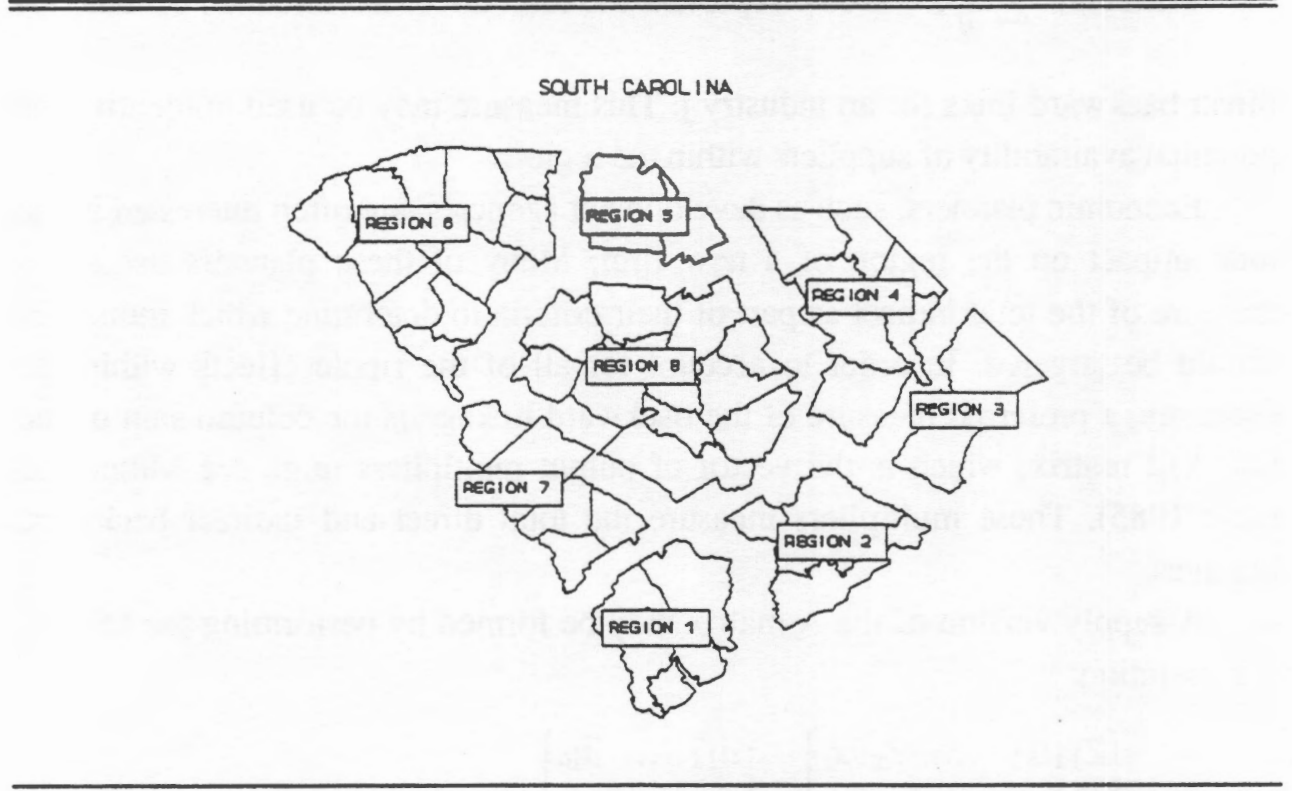

The linkage concept is intimately related to input-output analysis. ${ }^{8}$ If we consider the standard transactions matrix from an $\mathrm{I}-\mathrm{O}$ table, $\mathrm{Z}$, we may derive a measure of the backward and forward linkages.

Let $\mathbf{Z}$ be the matrix of input-output transactions:

$$
Z=\left\{\begin{array}{ccc}
Z_{11} & \ldots & Z_{\ln } \\
\vdots & \ddots & \vdots \\
Z_{n l} & \ldots & Z_{n n}
\end{array}\right\}
$$

where $\mathrm{Zij}=$ the amount of good $\mathrm{i}$ delivered to sector $\mathrm{j}$.

Let $X=\mathbf{a}$ vector of outputs.

Then the technical coefficients matrix, $\mathrm{A}$, is formed by the following procedure:

$$
A=\left\{\begin{array}{ccc}
Z_{11 / x_{1}} & \ldots & Z_{\ln } / x_{n} \\
\vdots & \ddots & \vdots \\
Z_{n} / x_{1} & \ldots & Z_{n n} / x_{n}
\end{array}\right\}=\left\{\begin{array}{ccc}
a_{11} & \ldots & a_{\ln } \\
\vdots & \ddots & \vdots \\
a_{n l} & \ldots & a_{n n}
\end{array}\right\}
$$


The sum, $\sum_{i=1}^{n} a_{i j}$, would represent the total direct intermediate demand, or direct backward links for an industry j. This measure may be used to identify the potential availability of suppliers within the region.

Economic planners, such as development agencies, are often interested in the total impact on the region of a new firm. Many of these planners use some measure of the total impact as part of their criteria to determine which industries should be targeted. In order to account for all of the ripple effects within the economy, a preferred measure of the backward linkage is the column sum of the (I - A $)^{-1}$ matrix, which is the vector of output multipliers (e.g., see Miller and Blair 1985). These multipliers measure the total direct and indirect backward linkages.

A supply version of the A matrix may be formed by performing the following operation:

$$
\bar{A}=\left\{\begin{array}{ccc}
Z_{11 / x_{1}} & \ldots & Z_{\ln } / x_{i} \\
\vdots & \ddots & \vdots \\
Z_{n l} / x_{n} & \ldots & Z_{n n} / x_{n}
\end{array}\right\}=\left\{\begin{array}{ccc}
\bar{a}_{11} & \ldots & \bar{a}_{\ln } \\
\vdots & \ddots & \vdots \\
\bar{a}_{n l} & \ldots & \bar{a}_{n n}
\end{array}\right\}
$$

The $\bar{a}_{i j}$ represent the amount of good i supplied to sector $j$ for each dollar of output produced by sector $i$. The direct forward linkage of sector $i$ is defined as the row sum of matrix $\bar{A}$. A measure of the total direct and indirect forward linkages is given by row sums of the matrix $(I-\bar{A})^{-1}$. In the supply-side approach to I-O models, these forward multipliers are called input multipliers (see Miller and Blair 1985). If the matrix includes a row for households and corresponding column for consumption, then this measure will capture the induced final demands also.

Ideally one would have available a regional A matrix for each of the eight substate regions under consideration. Typically, most researchers use the national I-O table to determine the interindustry linkages and then regionalize these measures to the local economy. ${ }^{9}$ We chose to utilize the multipliers from RIMS II to determine the backward and forward linkages. RIMS II is a well known and easily accessible I-O model. ${ }^{10}$ The technical coefficients, the A matrix, are not provided by RIMS. Rather, a table of multipliers are provided. These multipliers are regionalized for the county aggregation scheme used in our research. The multipliers include the total direct, indirect, and induced impacts. It should be noted that although the firm may not be particularly interested in the total backward 
linkage, an economic planner would be. Further, planners often use these measures as part of the criteria for targeting an industry. Our choice to use multipliers as our measure of linkages was determined by the convenience and accessibility of the multipliers and the fact that they are used in some targeting schemes. $^{11}$

The South Carolina State Development Board monitors announced capital investment within the state. These announcements include both new and existing plants. Our data, covering the years 1985-1988, were aggregated by two-digit SIC code and by region. Within the three years we investigated, there were a total of 831 usable announcements ${ }^{12}$ (see Table 1).

The size of the current industry already located in the region may act as a "pull factor," attracting new plants to locate within the region. The fact that other firms have located within the region may be a signal to the potential entrant that the region is in fact a profitable one. This signal thus reduces search costs for the firm. We measure this attractor by the relative size of employment in the manufacturing sector located within the region. The variable, percentage employment, is defined as follows:

$$
E_{i j} / \sum_{j=1}^{8} E_{i j}
$$

where $E_{i j}=$ the amount of employment in industry $i$ in region $j$.

$$
i=1, \ldots, 19 .
$$

The educational and skill level of the potential labor force is measured by the percentage of the region's population that is more than 25 years of age and has completed high school. Another characteristic of the potential labor force is the total number of workers engaged in the manufacturing process. This variable, manufacturing employment, captures three phenomena: (1) agglomeration economies; (2) labor resources; and (3) size of the region. The presence of a large number of manufacturing employees indicates potential agglomeration economies through the large concentration of manufacturing activities (captured in the number of employees). The number of manufacturing employees also indicates the potential labor pool upon which a new firm may draw. Many studies include some variable measuring size of the region to capture the effects due to size, or the dartboard theory. Bartik (1985), for example, used land area as a measure. Any 
TABLE 1

Sector Definitions and Number of Announced Investments

Code and Name

Number of Announced Investments (1985-1988)

SIC 20: Food products

33

SIC 21: Tobacco products

SIC 22: Textiles

SIC 23: Apparel

SIC 24: Lumber products

32

SIC 25: Furniture

SIC 26: Paper products $\quad 40$

SIC 27: Printing and publishing 25

SIC 28: Chemical products $\quad 117$

SIC 29: Petroleum and coal products 4

SIC 30: Rubber and miscellaneous plastics products $\quad 70$

SIC 31: Leather and leather products 0

SIC 32: Stone, clay, and glass products 37

SIC 33: Primary metal industries 41

SIC 34: Fabricated metal products 47

SIC 35: Machinery, except electrical 91

SIC 36: Electrical machinery 54

SIC 37: Transportation equipment 34

SIC 38: Scientific instruments 17

Investments by Region

Region 1: Low Country 14

Region 2: Charleston 52

Region 3: Grand Strand 21

Region 4: Pee Dee 111

Region 5: Charlotte-Rockhill 77

Region 6: Upstate $\quad 335$

Region 7: Augusta-Aiken 51

Region 8: Midlands 170

Total number of observations $\quad 831$ 
measure that captures size would serve as a means for controlling for the dartboard effect.

The effective property tax rate is proxied by the total property taxes collected in the region divided by the land area of the region. Potential labor costs were measured by the per capita income of the region. Transportation linkages within the region were measured by the total highway mileage in the region. ${ }^{16}$

\section{RESULTS AND DISCUSSION}

The results of the conditional multinomial regression are presented in Table 2. Both linkages, forward and backward, are significant. The backward linkage, measured by the backward multiplier, is significant at the 1 percent level. The presence of supply linkages increases the probability of a firm locating within the region. Thus, the inclusion of backward linkages in target industry studies, such as MRI, Battelle, and Anderson and Johnston (1992), is confirmed. Possible explanations for the significance of this variable are provided by just-in-time inventory procedures and potential transportation cost reduction. The demand linkage, measured by the forward multiplier, is significant at the 5 percent level. Many of the manufacturing firms located within the state do not produce for local final demand (or consumer demand). The size of their local market is then determined by the demands for intermediate goods generated by local industry.

The presence of existing firms within own SIC code, which is measured by the percentage of the state's employment within that code located within the particular region, is highly significant. Previous research has indicated that the existence of manufacturing firms within a region is a determinant of the location decision. There are several theoretical justifications for this observation. The presence of potential agglomeration economies is often cited. Another explanation is that the presence of existing firms confirms that the location is a desirable one. Thus, search cost is reduced by simply considering locations that have already proven to be desirable by other firms.

Total manufacturing employment within the region is significant and captures two concepts. The size of an appropriate labor pool is an important consideration in the location decision. Firms contemplating locating within an area are interested in the availability of a labor force. Further, by using the size of the labor force, we have also captured the relevance of the size of the region, the dartboard theory.

Per capita income is very significant and negative. This implies that, ceteris paribus, firms will locate in lower income areas. Given an adequate transportation system, sufficient linkages, and a potential work force, the region with the lower 
TABLE 2

Regression Results

\begin{tabular}{lc}
\hline \hline Variable & Coefficient \\
\hline Backward multiplier & $0.9976^{* * *}$ \\
& $(3.866)$ \\
Forward multiplier & $0.0243 * *$ \\
& $(2.313)$ \\
Percentage employment & $0.01753^{* * *}$ \\
& $(5.839)$ \\
Manufacturing employment & $0.000003^{* *}$ \\
& $(2.344)$ \\
Highway mileage & $0.000053^{* *}$ \\
& $(2.332)$ \\
Per capita income & $-0.2052^{* * *}$ \\
Percentage high school & $(-3.655)$ \\
& 0.0056 \\
Property tax & $(0.356)$ \\
& 0.0047 \\
Maximum likelihood estimates & $(0.507)$ \\
Log-likelihood & \\
Restricted (slopes =0) & -1379.7 \\
Log-likelihood & \\
Chi-squared (8 df) & -1728.0 \\
\hline
\end{tabular}

Notes: t-ratios are shown in parentheses.

*** Significant at the 1 percent level.

** Significant at the 5 percent level.

* Significant at the 10 percent level.

income level will be a more probable location. This would indicate that the firm is searching for the lower labor costs within the state.

Both the education attainment variable and the property tax variable are not statistically significant. We tried another specification for the property tax variable. When the tax rate was measured as the percent of total personal income paid in property taxes, we obtained the expected sign, i.e., negative; however, the variable was still insignificant. This result coincides with findings by Carlton (1983) 


\section{TABLE 3}

Elasticities:

Backward multiplier

Forward multiplier

Percentage employment

Manufacturing employment

Highway mileage

Per capita income

Percentage high school

Property tax

\section{Incremental Change:}

Backward multiplier

Forward multiplier

Percentage employment

Manufacturing employment

Highway mileage

Per capita income

Percentage high school

Property tax
$\% \Delta \mathbf{P}_{\mathbf{j}} / \% \Delta \mathbf{X}_{\mathbf{j}}$

1.4650

0.2204

0.1792

0.1152

0.2195

1.9996

0.6683

0.0777

$\mathbf{P}_{\mathbf{j}} / \% \Delta \mathbf{X}_{\mathbf{j}}$

0.172

0.036

0.036

0.258

0.037

$-0.219$

0.073

0.012

and McConnell and Schwab (1990), who found that the county property tax variable was either the wrong sign or insignificant. One would generally expect that educational attainment would be significant. We speculate that given the kind of manufacturing activities that generally take place in South Carolina, i.e., on the lower end of the technical skill scale, the availability of an experienced work force is more relevant to the location decision than the educational level of that work force. This accounts for the significance of the level of manufacturing employment within the region, while the educational attainment level is not significant.

The availability of adequate transportation is measured by the highway mileage within the region and is significant.

Table 3 presents the calculations of the elasticities and the incremental changes in probabilities. These values are the average values across the eight regions. The elasticity is calculated in the normal fashion. The backward multiplier and the 
per capita income variables are the most elastic; that is, the change in probability is more responsive to the change in one of these variables. Often a percent of a percent is difficult to interpret intuitively, so we also include the incremental change. We note that a 1 percent change in the size of the backward multiplier increases the probability of location by 17.2 percent, while a 1 percent increase in the size of the forward multiplier only increases the probability of location by 3.6 percent. A 1 percent change in per capita income reduces the probability of location by 21.9 percent.

\section{v. CONCLUSION}

The primary emphasis of this paper was to determine whether backward and forward linkages are relevant determinants in the location decision of manufacturing firms. Using a conditional multinomial logit model, we investigated this hypothesis at the substate level. We found that both types of linkages are significant, although the backward linkage was statistically more significant and also exerted a larger impact on the probability of locating within a particular region. Two variables representing labor force characteristics were also relevant: the per capita income within a region, which proxies labor costs, and the number of workers employed in manufacturing, which represents the size of the labor pool. The percentage of total employment in a given industry located within the region was also very significant.

We find that firms do consider linkages when deciding on plant location. As a policy tool, we find that the use of linkages as part of the targeting criteria is probably statistically valid. These conclusions may be limited to substate decisions, i.e., our research does not point to the significance of linkages in determining the choice of state.

\section{ENDNOTES}

1. Availability implies a notion of sufficient capacity. Backward linkages measures by an I-O table capture existing relationships among industries. Anderson and Johnston (1992) attempted to address the capacity constraint notion by evaluating how much of a supplier's output is exported compared to how much is sold within the region.

2. There may be some intrastate variation in some of these variables, particularly in energy costs. Property tax differentials we account for with a tax rate proxy. Local development incentives were not accounted for explicitly. However, 
following the suggestion of one referee, the model was respecified to incorporate unobserved (or omitted) region effects. Our measure of linkages remained a significant determinant of the location decision.

3. Blair and Premus (1987) note that the decision process is often a sequential one. On the macro level, the state or region is chosen. At the second level, micro factors become relevant. Our innovation is to consider the relevancy of linkages at the micro level.

4. McFadden (1974) pioneered this procedure. It has since become a standard took in the site location literature. For example, see Bartik (1985) and Carlton (1983). Haynes and Fotheringham (1991) provide a recent review of discrete choice models in regional analysis.

5. We have 831 observations. Using this specification, we have $8 \times 831$ lefthand side entries. Each successful location receives a value of 1 that corresponds with the locational characteristics of that region and a 0 for the other 7 regions.

6. Aggregating counties into regions can be somewhat of an ad hoc procedure. We based our aggregation scheme on commuting patterns, which provides a means of linking these counties into a region. We believe that the set of alternatives, besides being finite, is also well defined.

7. See Martin et al. (1991) for further detail on the characteristics of these regions. Previous research conducted in South Carolina has utilized this particular aggregation scheme.

8. Earlier research, such as Oksanen and William (1984), Goode (1986), Hastings and Goode (1982), and Anderson and Johnston (1992), use I-0 tables in the construction of their linkage measure.

9. Hastings and Goode (1982), for example, use employment and sales data in a variant of the location quotient concept to determine their linkage measure. Anderson and Johnston (1992) used sales data from American Business Directories to regionalize the I-O data from the national I-O table.I

10. RIMS II is a well known I-O model provided by the Bureau of Economic Analysis of the U.S. Department of Commerce. The output from RIMS II consists of the total sectoral impacts from 531 sectors distributed across $39 \mathrm{sec}-$ tors. The column sums of the matrix are the traditional output multipliers, which in our case represent the backward linkages. We used the row sums of the $39 \times 531$ multipliers as a proxy for the forward linkage.

11. By using this measure in our specification, we also are testing the validity of this linkage measure as a criterion in targeting industries.

12. For the purposes of this research, the actual size of the announced expansion is not relevant. Rather, the fact that a decision was made to locate in a particular region is what matters. The data for this project were acquired from the South Carolina State Development Board for the purposes of another project (see 
Martin et al. 1991) and were not coded as to whether the expansion was a new plant or an existing one. Thus, the data set includes both new and existing plant expansions. As Schemenner (1982) observes, firms have the choice to expand by either an on-site expansion or a relocation. At some point in the size of the expansion, the same decision criteria enter into the process of deciding where to expand. We only considered data for plant expansions of $\$ 1$ million or more.

13. The above data, which describe the characteristics of the regions, are found in the South Carolina Statistical Abstract (1990). Employment data, per capita income, highway mileage, and property taxes are 1986 data. Educational attainment data are from the 1980 Census.

\section{REFERENCES}

Anderson, Donald, and Stephen Johnston. "A Linkage Approach to Industrial Location." Growth and Change 23, no. 3 (1992): 321-333.

Bartik, Timothy. "Business Location Decisions in the United States: Estimates of the Effects of Unionization, Taxes, and Other Characteristics of States." Journal of Business and Economic Statistics 3, no. 1 (1985): 14-22.

Blair, John, and Robert Premus. "Major Factors in Industrial Location: A Review." Economic Development Quarterly 1, no. 1 (1987): 72-85.

Carlton, Dennis. "The Location and Employment Choices of New Firms: An Econometric Model with Discrete and Continuous Endogenous Variables." The Review of Economics and Statistics 65, no. 3 (1983): 440-449. . "Business Location Decisions in the United States: Estimates of the Effects of Unionization, Taxes, and Other Characteristics of States." Journal of Business and Economic Statistics 3, no. 1 (1985): 14-22.

Carlton, Dennis W. "Why Do Firms Locate Where They Do: An Econometric Model." In Interregional Movements and Regional Growth, edited by William Wheaton. Washington, D.C.: The Urban Institute, 1979.

Doescher, Taitha, Robert Dauffenbach, and Warner Larkin. "Identification of Target Industries for Industrial Recruiting in a Nonmetropolitan Area." Review of Regional Economics and Business (April 1986): 3-12.

Goode, Frank. "The Efficacy of More Refined Demand Variables in Industrial Location Models: Note." Growth and Change (January 1986): 66-75.

Hansen, Eric. "Industrial Location Choice in Sao Paulo, Brazil." Regional Science and Urban Economics 17 (1987): 89-108.

Hastings, Steven, and Frank Goode. "An Input Supply Approach: Improved Measures of Industrial Location Factors." Growth and Change 13, no. 4 (October 1982): 25-31. 
Haynes, Kingsley, and A. Stewart Fotheringham. "The Impact of Space on the Application of Discrete Choice Models." The Review of Regional Studies 20, no. 2 (Spring 1991): 39-49.

Latham, W.R. Locational Behavior in Manufacturing Industries. Leiden, Netherlands: Nijhoff, 1976.

Martin, Randolph, et al. Manufacturing and Economic Development: Interindustry Linkages in South Carolina. Division of Research, University of South Carolina, 1991.

McAleese, D., and D. McDonald. "Employment Growth and the Development of Linkages in Foreign-Owned and Domestic Manufacturing Enterprises." $O x$ ford Bulletin of Economics and Statistics 40, no. 4 (1978).

McFadden, Daniel. "Conditional Logit Analysis of Qualitative Choice Behavior." In Frontiers in Econometrics, edited by Paul Zarembka, 105-142. New York: Academic Press, 1974.

Miller, Ronald, and Peter Blair. Input-Output Analysis: Foundations and Extensions. Englewood Cliffs, N.J.: Prentice-Hall, 1985.

Minshall, Charles, and Cathy Wright. "An Approach for Identifying Target Industries and Implementing a Focused Economic Development Program." BATTELLE, Columbus, Ohio. Paper presented at the Southem Regional Science meetings, March 1990.

Morton, LaDene. "Midwest Research Institute's Target Industry Software, Targets, and the MRI Targeting Process." Paper presented at the Southem Regional Science meetings, March 1990.

Mulkey, David, and Ellen Hagey. "Input/Market Linkages and Organizational Structure: An Empirical Study." The Review of Regional Studies 17, no. 1 (Winter 1987): 33-43.

O'Farrell, P.N., and B. O'Loughlin. "New Industry Input Linkages in Ireland: An Economic Analysis." Environment and Planning A 13, no. 3 (1981): 285308.

O'hUallachain, B. "Linkages and Foreign Direct Investment in the United States." Economic Geography 60, no. 3 (1984): 238-53.

Oksanen, E.H., and J.R. Williams. "Industrial Location and Inter-IndustryLinkages." Empirical Economics 9 (1984): 139-150.

South Carolina State Statistical Abstract 1990. South Carolina Division of Research and Statistical Services, 1990.

Wasylenko, Michael, and Therese McGuire. "Jobs and Taxes: The Effect of Business Climate on States' Employment Growth Rates." National Tax Journal 38, no. 4 (December 1985): 497-511. 
Woodward, Douglas P. "Locational Determinants of Japanese Manufacturing Start-ups in the United States" Southern Economic Journal 58, no. 3 (January 1992): 690-708. 